\title{
Efektifitas Penerapan Diabetes Self Management Education (DSME) Terhadap Motivasi Penderita Dalam Mencegah Kekambuhan dan Komplikasi Penyakit Diabetes Melitus
}

\author{
Siti Damawiyah \\ Universitas Nahdlatul Ulama Surabaya, damasiti@unusa.ac.id \\ Yurike Septianingrum \\ Universitas Nahdlatul Ulama Surabaya, yurike@ unusa.ac.id
}

\begin{abstract}
Abstrak
Diabetes melitus merupakan penyakit kronis yang masih menjadi masalah utama dalam kesehatan baik di dunia maupun di Indonesia. Diabetes mellitus adalah suatu kelompok penyakit metabolik dengan karakteristik hiperglikemia yang terjadi karena kelainan sekresi insulin, kerja insulin atau kedua-duanya. Tujuan penelitian ini adalah mengetahui pengaruh penerapan Diabetes Self Management Education (DSME) terhadap motivasi penderita dalam mencegah kekambuhan dan komplikasi penyakit diabetes melitus di RW 01 Kelurahan Wonokromo Surabaya. Desain penelitian menggunakan Quasy Experimental, Control Group Pre Test-Post Test Design. Populasinya adalah penderita penyakit diabetes melitus sebanyak 24 orang. Sampel dalam penelitian ini adalah sebagian penderita DM yang memenuhi kriteria sebanyak 10 orang kelompok intervensi dan 10 orang kelompok kontrol. Variabel independen dalam penelitian ini adalah penerapan DSME, variabel dependen dalam penelitian ini adalah motivasi penderita dalam mencegah kekambuhan dan komplikasi penyakit DM. Analisa data menggunakan uji Mann Withney. Hasil penelitian menunjukkan bahwa motivasi kelompok perlakuan sebelum diberikan DSME memiliki nilai baik $0 \%$ dimana nilai tersebut lebih kecil dibanding nilai motivasi sesudah responden diberikan DSME yaitu sebesar $60 \%$. Sedangkan motivasi kelompok kontrol saat observasi awal memiliki nilai baik $0 \%$ dan saat observasi akhir memiliki nilai baik $10 \%$. Peningkatan nilai motivasi tersebut meningkat lebih kecil dibanding penilaian nilai motivasi kelompok perlakuan yaitu sebesar 60\%. Penerapan DSME meningkatkan motivasi penderita dalam mencegah kekambuhan dan komplikasi penyakit diabetes mellitus. DSME bisa menjadi acuan dalam program edukasi kesehatan untuk meningkatkan pengetahuan dan ketrampilan perawatan mandiri pasien DM.
\end{abstract}

Kata kunci: Diabetes Mellitus, Self Management, Pendidikan, Motivasi

\begin{abstract}
Diabetes mellitus is a chronic disease that is still a major problem in health both in the world and in Indonesia. Diabetes mellitus is a group of metabolic diseases with characteristics of hyperglycemia that occur due to abnormal insulin secretion, insulin action or both. The purpose of this study was to determine the effect of the application of Diabetes Self Management Education (DSME) on patient's motivation in preventing recurrence and complications of diabetes mellitus in RW 01, Wonokromo Village, Surabaya. Research design using the Quasy Experimental, Pre Test-Post Test Design Control Group. The population in this study were 24 people with diabetes mellitus. The sample in this study were some DM patients who met the criteria of 10 intervention groups and 10 control groups. The independent variable in this study was the application of DSME, the dependent variable in this study was the motivation of patients to prevent recurrence and complications of DM disease. Data analysis using the Mann Withney test. The results showed that the motivation of the treatment group before being given DSME had a good value of $0 \%$ where the value was smaller than the value of motivation after the respondent was given DSME that is equal to 60\%. While the motivation of the control group when the initial observation has a good value of $0 \%$ and when the final observation has a good value of $10 \%$. The increase in motivation value increased smaller than the
\end{abstract}


assessment of the motivation value of the treatment group, which was $60 \%$. DSME application increases patient motivation in preventing recurrence and complications of diabetes mellitus. DSME can be used as a health promotion program to improve self-care capabilities of DM patients.

Keywords: Diabetes, Self Management, Education, Motivation

\section{PENDAHULUAN}

Diabetes melitus (DM) merupakan penyakit kronis yang masih menjadi masalah utama dalam kesehatan baik di dunia maupun di Indonesia. DM adalah suatu kelompok penyakit metabolik dengan karakteristik hiperglikemia yang terjadi karena kelainan sekresi insulin, kerja insulin atau kedua-duanya. DM merupakan suatu penyakit kronis yang mempunyai dampak negatif terhadap fisik maupun psikologis klien, gangguan fisik yang terjadi seperti poliuria, polidipsia, polifagia, mengeluh lelah dan mengantuk (Price \& Wilson, 2005). Lebih dari 90 persen dari semua populasi diabetes adalah diabetes melitus tipe 2 yang ditandai dengan penurunan sekresi insulin karena berkurangnya fungsi sel beta pankreas secara progresif yang disebabkan oleh resistensi insulin (American Diabetes Association, 2010).

\section{Menurut World Health} Organization/ WHO (2012) bahwa jumlah klien dengan DM di dunia mencapai 347 juta orang dan lebih dari $80 \%$ kematian akibat DM terjadi pada negara miskin dan berkembang. Hasil penelitian yang dilakukan pada seluruh provinsi yang ada di Indonesia menunjukkan bahwa prevalensi nasional untuk toleransi glukosa tertanggu (TGT) adalah sebesar 10,25\% dan untuk DM adalah sebesar 5,7\% (Balitbang Depkes RI, 2008).

Laporan dari Badan Penelitian dan Pengembangan Kesehatan Kementrian Kesehatan berupa Riset Kesehatan Dasar (Riskesdas) tahun 2013 menyebutkan terjadi peningkatan prevalensi klien diabetes melitus pada tahun 2007 yaitu 1,1\% meningkat pada tahun 2013 menjadi 2,4\%. Diabetes mellitus disebabkan karena gangguan kemampuan tubuh untuk menggunakan glukosa ke dalam sel, sehingga glukosa menumpuk dalam darah. Pada diabetes tipe 1, gangguan ini disebabkan karena pankreas tidak dapat memproduksi insulin. Sedangkan pada diabetes tipe 2, gangguan ini terjadi akibat tubuh tidak efektif menggunakan insulin atau kekurangan insulin yang relatif dibandingkan kadar glukosa darah. Kadar glukosa yang tinggi ini dapat merusak pembuluh darah kecil di ginjal, jantung, mata, dan sistem saraf, sehingga mengakibatkan berbagai komplikasi.

Diabetes tipe 1 dan 2 dapat menyebabkan komplikasi berupa kerusakan retina mata, kerusakan saraf, 
penyakit stroke dan jantung koroner, kerusakan ginjal, disfungsi seksual, keguguran, atau bayi lahir mati dari ibu yang menderita diabetes. Meningkatnya penyakit kronis diantaranya penyakit diabetes, memerlukan manajemen yang baik sehingga tatalaksana penyakit tersebut dapat efektif, salah satu strategi yang dapat dilaksanakan adalah dengan melakukan edukasi yang memiliki tujuan jelas dan pasien terlibat dalam proses pelayanan kesehatan yang mereka terima. Edukasi kesehatan adalah kegiatan yang sengaja dirancang dengan tujuan untuk pencapaian pada kesehatan atau penyakit yang berhubungan dengan pembelajaran, dan beberapa relatif membuat perubahan permanen dalam kemampuan dan disposisi individu. Efektivitas edukasi kesehatan dapat mengubah pengetahuan dan pemahaman cara berpikir, yang mungkin dapat berdampak pada perubahan perilaku atau gaya hidup. Program edukasi pada penderita DM yang tepat adalah DSME.

Menurut Sidani \& Fan (2009), DSME merupakan suatu proses memberikan pengetahuan kepada pasien mengenai aplikasi strategi perawatan diri secara mandiri untuk mengoptimalkan kontrol metabolik, mencegah komplikasi, dan memperbaiki kualitas hidup pasien DM.

\section{METODE}

Penelitian ini merupakan jenis penelitian kuantitatif dengan menggunakan desain Quasy Experimental, Control Group Pre Test-Post Test Design. Penelitian ini bertujuan membandingkan pengaruh penerapan DSME terhadap motivasi penderita dalam mencegah kekambuhan dan komplikasi penyakit diabetes mellitus. Populasi dalam penelitian ini adalah penderita penyakit diabetes melitus sebanyak 24 orang. Sampel dalam penelitian ini adalah sebagian penderita diabetes mellitus sebanyak 20 orang yang kemudian dibagi menjadi 10 orang untuk kelompok eksperimen dan 10 orang untuk kelompok kontrol. Cara pengambilan sampel dalam penelitian ini menggunakan consecutive sampling. Penelitian ini mengambil lokasi di wilayah RW 01 Kelurahan Wonokromo Surabaya. Penelitian dilakukan pada bulan April-Juni 2019. Variabel independen dalam penelitian ini adalah penerapan DSME. Variabel dependen dalam penelitian ini adalah motivasi penderita dalam mencegah kekambuhan dan komplikasi penyakit DM. Analisis perbandingan motivasi kelompok eksperimen sebelum dan sesudah diberikan DSME menggunakan uji Mann Withney. Analisis kontrol sebelum dan sesudah dilakukan observasi tanda dan gejala penyakit menggunakan uji Mann Withney. Tingkat kemaknaan $(\alpha)$ yang digunakan adalah 0,05 . 


\section{HASIL PENELITIAN}

A. Motivasi penderita dalam mencegah kekambuhan sebelum dan sesudah diberikan DSME

Tabel 4.2 Motivasi penderita diabetes mellitus dalam mencegah kekambuhan sebelum dan sesudah diberikan DSME

\begin{tabular}{lllllllll}
\hline Motivasi & \multicolumn{4}{c}{ Perlakuan } & \multicolumn{3}{c}{ Kontrol } \\
\cline { 2 - 9 } & $\begin{array}{l}\text { Kurang } \\
(\%)\end{array}$ & $\begin{array}{l}\text { Cukup } \\
(\%)\end{array}$ & $\begin{array}{l}\text { Baik } \\
(\%)\end{array}$ & $\begin{array}{c}\mathrm{N} \\
(\%)\end{array}$ & $\begin{array}{c}\text { Kurang } \\
(\%)\end{array}$ & $\begin{array}{c}\text { Cukup } \\
(\%)\end{array}$ & $\begin{array}{l}\text { Baik } \\
(\%)\end{array}$ & $\begin{array}{c}\mathrm{N} \\
(\%)\end{array}$ \\
\hline Sebelum & $5(50)$ & $5(50)$ & $0(0)$ & $10(100)$ & $4(40)$ & $6(60)$ & $0(0)$ & $10(100)$ \\
Sesudah & $0(0)$ & $4(40)$ & $6(60)$ & $10(100)$ & $2(20)$ & $7(70)$ & $1(10)$ & $10(100)$ \\
\hline
\end{tabular}

Sumber: Data primer, April - Juni 2019

Berdasarkan tabel 4.2 dapat diketahui bahwa motivasi kelompok perlakuan sebelum diberikan DSME memiliki nilai baik $0 \%$ dimana nilai tersebut lebih kecil dibanding nilai motivasi sesudah responden diberikan DSME yaitu sebesar $60 \%$. Hal ini menunjukkan bahwa motivasi responden sesudah diberikan

B. Pengaruh penerapan DSME terhadap motivasi penderita di dalam mencegah kekambuhan dan komplikasi penyakit diabetes melitus

Tabel 4.3 Pengaruh penerapan DSME terhadap motivasi penderita di dalam mencegah kekambuhan dan komplikasi penyakit diabetes mellitus

\begin{tabular}{lcccc}
\hline \multirow{2}{*}{ Kesiapan } & \multicolumn{2}{c}{ Perlakuan } & \multicolumn{2}{c}{ Kontrol } \\
\cline { 2 - 5 } & $\begin{array}{c}\text { Sebe } \\
\text { lum }\end{array}$ & $\begin{array}{c}\text { Sesu } \\
\text { dah }\end{array}$ & $\begin{array}{c}\text { Sebe } \\
\text { lum }\end{array}$ & $\begin{array}{c}\text { Sesu } \\
\text { dah }\end{array}$ \\
\hline a. Baik (\%) & 0 & 60 & 0 & 10 \\
\hline $\begin{array}{l}\text { b. Nilai p Mann } \\
\quad \text { Whitney }\end{array}$ & 0,01 & & 0,13 & \\
\hline c. Odd Ratio & & 6,8 & & \\
\hline
\end{tabular}

Sumber: Data primer, April - Juni 2019

$$
\text { Berdasarkan tabel } 4.3 \text { dapat }
$$

diketahui bahwa pada kelompok perlakuan hasil uji statistik dengan Mann Whitney didapatkan nilai $\mathrm{p}=0,01$, dimana nilai $\mathrm{p}<$
DSME menjadi lebih baik dibandingkan sebelum diberikan. Sedangkan motivasi kelompok kontrol saat observasi awal memiliki nilai baik $0 \%$ dan saat observasi akhir memiliki nilai baik 10\%. Peningkatan nilai motivasi tersebut meningkat lebih kecil dibanding penilaian nilai motivasi kelompok perlakuan yaitu sebesar $60 \%$.

0,05 yang berarti terdapat pengaruh motivasi penderita sebelum dan sesudah diberikan DSME. Sedangkan pada kelompok kontrol hasil uji statistik dengan uji Mann Whitney didapatkan nilai $\mathrm{p}=$ 0,13 dimana nilai $\mathrm{p}>0,05$ yang berarti tidak terdapat pengaruh motivasi penderita. Hasil perhitungan odd ratio menunjukkan bahwa pemberian DSME mempunyai peluang 6,8 kali lebih besar untuk meningkatkan motivasi penderita diabetes melitus.

\section{PEMBAHASAN}

Berdasarkan tabel 4.2 dapat diketahui bahwa motivasi kelompok perlakuan sebelum diberikan DSME memiliki nilai 
baik $0 \%$, sedangkan motivasi kelompok kontrol saat observasi awal juga memiliki nilai baik $0 \%$. Nilai motivasi yang sama pada kedua kelompok dapat disebabkan oleh beberapa faktor, salah satunya adalah pengetahuan dan pengalaman yang sama mengenai konsep dasar dan perawatan mandiri penyakit DM. Beberapa responden menyatakan bahwa mereka telah berobat dan melakukan perawatan mandiri sesuai yang diajarkan oleh perawat puskesmas atau dokter tempatnya berobat, namun perawatan mandiri yang dilakukan hanya sebatas kontrol gula darah dan olahraga ringan (Data Primer, 2019).

Berdasarkan tabel 4.2 dapat diketahui bahwa motivasi kelompok perlakuan sebelum diberikan DSME memiliki nilai baik $0 \%$ dimana nilai tersebut lebih kecil dibanding nilai motivasi sesudah responden diberikan DSME yaitu sebesar 60\%. Hal ini menunjukkan bahwa motivasi responden sesudah diberikan DSME menjadi lebih baik dibandingkan sebelum diberikan. Sedangkan motivasi kelompok kontrol saat observasi awal memiliki nilai baik $0 \%$ dan saat observasi akhir memiliki nilai baik 10\%. Peningkatan nilai motivasi tersebut meningkat lebih kecil dibanding penilaian nilai motivasi kelompok perlakuan yaitu sebesar $60 \%$.
Edukasi diberikan yang berupa DSME dapat mendukung pasien dalam mengambil keputusan, berperilaku peduli terhadap diri sendiri (self-care), memecahkan masalah, dan berkolaborasi aktif dengan tim tenaga kesehatan demi tercapainya perbaikan klinis, status kesehatan dan kualitas hidup. Materi yang dapat disampaikan kepada pasien mencakup nutrisi, aktivitas fisik, terapi farmakologi, pemantauan kadar glukosa darah, dan manajemen psikososial. Pemantauan kadar glukosa darah yang dilakukan secara rutin di rumah dapat membantu pasien dalam menyesuaikan asupan makan, aktivitas fisik, dan dosis obat/insulin dalam mencapai kontrol glukosa darah sehari-hari. Maka dengan mengontrol gula darah tidak hanya dapat memperbaiki kualitas hidup pasien tetapi juga dapat mengurangi biaya pengobatan penyakit diabetes. Diabetes sendiri merupakan kondisi di mana pankreas tidak dapat memproduksi insulin sendiri atau tidak mampu lagi menggunakan insulin yang ada di tubuh. Insulin digunakan untuk mengubah glukosa menjadi energi. Akibatnya apabila menderita diabetes akan memiliki risiko terkena beberapa komplikasi penyakit seperti penyakit jantung, gangguan penglihatan, gangguan ginjal, dan gangguan syaraf. 
Edukasi dan promosi kesehatan sangat perlu dilakukan pada diabetes mellitus tipe 2 karena penatalaksanaan yang bersifat komprehensif, meminum obat secara teratur, serta kontrol rutin secara berkala merupakan kunci untuk menjaga gula darah pasien tetap stabil sehingga menurunkan risiko komplikasi. Pasien perlu diedukasi untuk menghindari gula dan asupan lemak jenuh, rokok, dan alkohol. Pasien perlu menjaga berat badannya di kisaran indeks massa tubuh (IMT) normal serta berolahraga secara teratur, setidaknya 30 menit selama 3 kali seminggu. Pasien juga perlu diedukasi bahwa diabetes mellitus tipe 2 merupakan penyakit kronis yang belum dapat disembuhkan namun dengan perubahan gaya hidup dan pengobatan teratur, penyakit ini dapat dikontrol sehingga tidak menyebabkan komplikasi. Untuk itu, pasien perlu dimotivasi untuk minum obat secara terus-menerus walau tidak merasa sakit, kontrol rutin setiap 3-6 bulan, dan melakukan pemeriksaan kaki dan mata secara berkala. Promosi kesehatan untuk diabetes mellitus tipe 2 mencakup promosi gaya hidup sehat, pola makan, serta berolahraga secara teratur dan berhenti merokok dan minum alkohol. Dukungan psikologi oleh tenaga professional juga dapat diberikan, khususnya jika terjadi komplikasi pada pasien.
Berdasarkan tabel 4.3 dapat diketahui bahwa pada kelompok perlakuan hasil uji statistik dengan Mann Whitney didapatkan nilai $\mathrm{p}=0,01$, dimana nilai $\mathrm{p}<$ 0,05 yang berarti terdapat pengaruh motivasi penderita sebelum dan sesudah diberikan DSME. Sedangkan pada kelompok kontrol hasil uji statistik dengan uji Mann Whitney didapatkan nilai $\mathrm{p}=0,13$ dimana nilai $\mathrm{p}>0,05$ yang berarti tidak terdapat pengaruh motivasi penderita. Hasil perhitungan odd ratio menunjukkan bahwa pemberian DSME mempunyai peluang 6,8 kali lebih besar untuk meningkatkan motivasi penderita diabetes melitus. Hasil ini juga menunjukkan bahwa ada pengaruh penerapan DSME terhadap penurunan resiko komplikasi terjadi pada pasien DM.

\section{SIMPULAN}

Motivasi penderita dalam mencegah kekambuhan dan komplikasi penyakit diabetes mellitus sebelum diberikan DSME sebagian besar kurang. Motivasi penderita dalam mencegah kekambuhan dan komplikasi penyakit diabetes mellitus sesudah diberikan DSME sebagian besar baik. Ada pengaruh penerapan DSME terhadap motivasi penderita dalam mencegah kekambuhan dan komplikasi penyakit diabetes mellitus. DSME bisa menjadi acuan dalam program edukasi kesehatan untuk meningkatkan 
pengetahuan dan ketrampilan perawatan mandiri pasien DM.

\section{REFERENSI}

American Diabetes Association. 2010. Position statement: Standards of Medical Care in Diabetes. Diabetes Care (33).

Arief, F. 2008. Profil Penderita Diabetes Mellitus dengan Ulkus Kaki di SMF Penyakit Dalam RSUD dr. Soebandi Jember Periode Januari 2003 Desember 2007. [skripsi]. Jember: Fakultas Kedokteran Universitas Jember.

Asmadi. 2008. Konsep dasar keperawatan. Jakarta: EGC.

Efendi, F. dan Makhfudli. 2009. Keperawatan Kesehatan Komunitas: Teori dan Praktik dalam Keperawatan. Jakata: Salemba Medika.

Guyton, A. C. \& Hall, J. E. 1997. Buku Ajar Fisiologi Kedokteran Edisi 9. Terjemahan oleh Irawati Setiawan, dkk. Jakarta: EGC.

Haas, L., et.al. 2012. National Standards for Diabetes Self-Management Education and Support. Diabetes Care Volume 35: p. 2393-2401. thinking in client care,Edisi 4. New Jersey: Pearson Prentice Hall.

Mansjoer, A., dkk. 2005. Kapita Selekta Kedokteran. Jakarta: Media Aesculapius.

Maulana, H. D. J. 2009. Promosi Kesehatan. Jakarta: EGC.

McGowan, P. 2011. The Efficacy of Diabetes Patient Education and SelfManagement Education in Type 2 Diabetes. Canadian Journal of Diabetes Volume 35 (1): p. 46-53.

Norris, S. L., et.al. 2002. Increasing Diabetes Self-Management Education in Community Settings. Am $J$ Prev Med Volume 22 (4S): p. 39-66.

Notoatmodjo, S. 2003. Pendidikan dan Perilaku Kesehatan. Jakarta: Rineka Cipta.

Notoatmodjo, S. 2007. Promosi Kesehatan dan Ilmu Perilaku. Cetakan Pertama. Jakarta: Rineka Cipta.

Notoatmodjo, S. 2010. Metode Penelitian Kesehatan. Jakarta: Rineka Cipta.

Nursalam. 2008. Konsep dan Penerapan Metodologi Penelitian Ilmu Keperawatan: Pedoman Skripsi, Tesis, dan Instrumen Penelitian Keperawatan. Jakarta: Salemba Medika.

Potter, P. A. \& Perry, A. G. 2005. Buku Ajar Fundamental Keperawatan: konsep, proses, dan praktik. Jakarta: EGC.

Price, S. A. \& Wilson, L. M. 2005. Patofisiologi: Konsep Klinis ProsesProses Penyakit Volume 2, Edisi 6. Terjemahan oleh Brahm U. Pendit, dkk. Jakarta: EGC.

Sastroasmoro \& Ismael. 2010. Dasar-dasar Metodologi Penelitian Klinis. Edisi-3 Jakarta: Bina Rupa Aksara.

Setiadi. 2007. Konsep \& Penulisan Riset Keperawatan. Yogyakarta: Graha Ilmu.

Sidani, S. \& Fan, L. 2009. Effectiveness of Diabetes Self-management Education Intervention Elements: A Metaanalysis. Canadian Journal of Diabetes Volume 33 (1): p. 18-26.

Smeltzer, S. C., \& Bare, B. G. 2001. Buku Ajar Keperawatan Medikal-Bedah Brunner dan Suddarth Volume 2, Edisi 8. Terjemahan oleh Agung Waluyo, dkk. Jakarta: EGC.

Sugiyono. 2012. Statistika Untuk Penelitian. Bandung: Alfabeta. 